\title{
$\left.7\right|_{\text {Conchusion }}$
}

This book has, we hope, destroyed two straw men that are common in debates about intergenerational equity, spending and health. The first is the myth of 'greedy geezers' - the stereotype of a pampered pensioner, living off lavish old-age provision including fine health care, while voting against investments in future generations. The second is the myth of unsustainability - of health care costs driven by ageing that make it impossible to finance a welfare state. The two straw men arguments come together in a call for cuts to public health care and other public service provision: the former by demonizing older people, the latter by suggesting that public provision, unlike private finance, is unsustainable. The images of greedy older people and an ineluctably increasing financial burden associated with ageing both strengthen the argument against public provision.

The economics and health system analysis behind this argument is weak. An ageing society need not affect health care much. In fact, as we suggested in the Introduction, there is no meaningful question about the best policy or priority that is answered by focusing on ageing. Obviously, planning long-term care or developing the health workforce or designing accessible spaces are activities in which demographic change matters, but they are properly understood as relatively technical problems that can be solved without major political change. Claims that policy or politics inexorably leads to a clash of generations are simply wrong, belied by policy analysis, political practice and the behaviour of people.

Instead, it is possible to envision both win-win policies and win-win politics. Win-win policies are those which invest in people across the life-cycle, avoiding false choices by targeting the conditions of health and wellbeing at any age. Win-win politics, meanwhile, simply avoid assuming that there is a zero-sum conflict between generations, which is easy because in neither health policy nor electoral behaviour does any such conflict necessarily exist. The origin of zero-sum, win-lose, politics lies in elite and interest group coalitions that furnish the supply 
of political ideas. This chapter recaps the reasons why win-lose politics need not happen and make a poor descriptive theory of ageing politics, and then argues for a focus on broad public policies that can create win-win or win-lose policies.

\subsection{Tearing Down Straw Men}

So why are the straw men made of straw? The first and simplest reason why is that we all age, and in fact are doing so every day. That means age cannot be a stable political cleavage. While marketers have done wonders to persuade the media that generations have stable characteristics (boomers, Generation X, Millennials, etc.), there is little evidence of that. Meanwhile, families redistribute resources across generations, tying people together and redefining their interests in ways that extend people's time horizons and draw upon better motivations than simple avarice.

The second reason is that older people are heterogeneous. There is heterogeneity between countries. Put simply, the narrative of greedy pensioners sunning themselves in the Mediterranean is very much a Western European one. It is a nonsensical idea for much of Central and Eastern Europe, where poverty among the elderly is a serious issue and the scale of unmet health needs suggests that health services are not disproportionately catering to them. Even between rich Western European states there is considerable heterogeneity. The experience of older people, their health status and use of health care, and their financial situation are all quite different from country to country. Even getting to be old at all varies and is substantially predicted by other, well-known inequalities such as income, place and race. The relatively inflamed intergenerational politics of the UK and USA, however influential they may be in English-language debates, are an outlier and not a harbinger.

There is also heterogeneity within countries. One of the most alarming findings we present is that there is a positive relationship between inter- and intragenerational inequality: countries with overall social spending more skewed towards the elderly are the ones with more inequality among the elderly. The countries with the most rhetoric about the unjustly good lifestyle of pensioners, and the most striking flow of public resources to the over-65s, are precisely the countries with the most pensioner poverty.

The third reason the straw men are made of straw is that the whole argument about greedy older people depends on a popular model of 
politics that good political science will not sustain. To claim that a large bloc of older voters is shaping public policy to their tastes, against the interest of others, is to claim that (1) older voters have homogeneous interests shaped by their age as against other issues such as wealth, gender or labour market position; (2) that they vote on these interests; and (3) that politicians deliver policies in response to their interests. None of these three assertions has strong empirical justification. There is no reason to believe, and no evidence, that political identities and policy preferences are primarily shaped by age. Not only are political identities much more complex and citizens often uninterested in much policy, but ageing itself means different things for the sicker, healthier, richer, poorer, etc. Even when people think about age, they are likely to personalize it and think about their families, which span generations. Selfishness is not just hard to translate into concrete policy, it is not even all that demonstrably popular.

The reason is even more important for understanding politics: there is little reason to believe in the underlying demand-side model of politics in which politicians identify the preferences of the electorate and then cater to them (Gilens, 2012; Hacker \& Pierson, 2014; Mair, 2013) ${ }^{1}$. Far superior are models in which politics happens at the level of elites such as party leaders, major interest groups and policy entrepreneurs. Their interaction, which can be understood in a variety of established political science theories, produce the 'supply' of policy demands and shape the political agenda including the salience and content of debates about health care and ageing. Voters do not formulate their own lists of policy demands and ask politicians to deliver them; rather, politicians develop policy 'offers' that balance their electoral interests against other issues such as coalitional politics amongst elites, and constraints such as fiscal pressure. Satisfying coalitional allies and bond markets, making targeted electoral offers and managing relations with other politicians are all much more concrete, observable and powerful explanations of political activity than a search for the mythical demands of a mythical

\footnotetext{
${ }^{1}$ These are median voter models, akin to representative agent thinking in economics, in which politicians are assumed to cater to the interests of the median voter, a fictitious creature whose existence depends on the assumption that voters are neatly aligned on a single axis with a median. The attraction of this model is not in its realism or usefulness, but in the way it can convert the entire electorate into a single agent (the median voter), and posit a gravitational pull towards centrist policy.
} 
and remarkably policy-literate median voter. They also fit with the fact that there is no single axis on which voters easily align; politicians and the media can change the subject, elevating topics which work for their interests and repressing inconvenient ones (thus, for example, making immigration and crime more prominent on the agenda is often an explicit strategy of parties on the right that benefit when the attention is there). Put another way: if polling data or median voters drove politics, the USA would have universal and equitable health care access and most countries would have universal jobs guarantees.

\subsection{Equity, Intergenerational and Other}

Political elites are expert in changing the subject. When any policy argument puts the spotlight on one issue, we should ask what is being left in the dark. In the case of a focus on the politics of ageing and health, the price of a focus on intergenerational inequality is a loss of focus on almost every other dimension of inequality. It is not hard to see why people whose policy goal is to shrink public health care provision and expose more people to the market would want to foment intergenerational conflict. What if we do not listen to them, and instead ask what other kinds of inequality are at work, shaping life chances and the politics of ageing?

There are many. Racial and ethnic inequalities shape life chances and, in the context of the politics of ageing, also shape the likelihood that people at any stage of the life-course are helped or helping, for free or for often inadequate pay. Citizenship exacerbates these inequalities, since one way to reduce the cost of care is to exploit undocumented people or others with precarious citizenship. Gender inequalities are enormous in the context of ageing, since the preponderance of paid and unpaid care is delivered by women, with consequences for their own health, wellbeing and labour market status. Above all, income and wealth inequalities are at work. The stronger and more universal the public provision, the less it matters how much money a family has, and the less likely it is that costs associated with ageing fall upon a family in a way that does real damage. This is important because a family's wealth, in particular, can be wiped out by the costs of long-term care. Resetting the inheritance of many families to zero every generation in order to pay for long-term care should have effects on long-term mobility and stability. 
Chapters 5 and 6 approached this issue, urging us to keep our eye on the much larger issues obscured by a focus on ageing, in particular the inequalities and equity issues that, unlike generations, do actually matter. When we put the spotlight on generations, we illuminate very little at the price of obscuring the important issues.

\subsection{After the Straw Men: Understanding the Politics of Ageing and Health}

Other inequalities and heterogeneity shape political identities, politics and policies more than generations. Policies matter in shaping the interaction of ageing with those other, more consequential, inequalities. Much of the evidence is in how much states matter: the scale of interstate heterogeneity in cross-section. A place like the BelgianFrench-Luxembourg-Netherlands border region might look integrated and relatively undifferentiated, but the lives of citizens at every age are quite different on different sides of those likes.

Much evidence is also in change, and that is most promising for our analyses. Policy and political change are constant, and create constantly changing opportunities as well as constraints on political creativity. Chapter 4 focused on change as well as interstate differences. It finds some constants: benefits to the aged hold up under austerity better than other kinds of benefits, presumably because of the political, human and other costs of reducing benefits to people who have left the labour market and are unlikely to return. But changes are also interesting: under what circumstances do win-win solutions appear?

From this perspective, creating and mobilizing intergenerational conflict is a political and policy strategy. The simple strategy, much discussed in the pensions literature, is to cut future pensions by leaving pension entitlements alone for current pensioners. Thus, younger generations will have higher retirement ages, lower benefits and more exposure to individual private pensions. This is more or less a formula for creating intergenerational conflict, since it asks people in some specific cohorts to finance a state pension system at benefit levels that they will not experience. It is likely that any intergenerational polarization it creates is still less consequential than political identities shaped by other factors that are more deeply embedded in people's lives and in society. Health benefits are difficult to cut in this way because health care systems in most countries are relatively unified and hard to divide 
at any level (from high-level structures to the internal cross-subsidies within hospitals) but many of the policy techniques can also work in education, housing, and long-term care, with long-run bad results.

Equally, a focus on assembling coalitions in favour of win-win solutions changes the kinds of political thinking that is required. Consider, for example, the interaction of gender, work, and care. Gender inequalities are present in every policy conversation, but especially every conversation to do with ageing because women are disproportionately responsible for paid and unpaid caring. Policy in the interests of women should take this into account, and also try to change it. Dependency ratios depend on female labour force participation as well as the size of cohorts. Unpaid caring labour, whether it is children caring for parents, grandparents caring for grandchildren, or something else, is disproportionately done by women. Paid caring labour is likewise feminized, and becomes more so in the areas of the labour market that are less prestigious, protected and paid, such as home health aides or much of the workforce in nursing homes. All of this means that organizations concerned with the situation of women in society have multiple interests in the definition of ageing, the ageing policy agenda and the policies adopted. It is possible to imagine narrowly class-based definitions of women's interests, in which the interest of well-off working women in having cheap child and elder care is prioritized, but it is also possible to imagine, and in some countries see, much more encompassing approaches that align the interests of working women (in support for their family and work roles), paid carers (in salary and good conditions) and older people (in good support). The class-based approach simply offloads duties from overburdened working women onto less well-off working women, but women's organizations could also opt for broader coalitions and policies that are more inclusive and sustainable and permit coalitions with unions (representing the paid carers), providers who see benefit in offering a better quality product, and representatives of immigrants, who often are the paid carers. In other words, there is immense scope and incentive for interest groups to adopt a broader and more enlightened approach in their own self-interest.

\subsection{Getting to a Win-Win}

Bringing together the themes in this book, we can phrase our thesis so far as: there is no really important question about the politics of health that is best answered by analysing the politics of ageing. Nor does it 
work to infer politics, let alone policies, from demographics: people do not have or feel that they have clear interests shaped by demography and policymaking is driven by supply rather than demand. Instead, the right focus for explaining policies is on the supply side: the coalitions of policymakers and interest groups that put particular issues and policy ideas on the agenda.

One step is policy ideas: what are the policies that are win-win, that successfully balance interests that are often occluded, such as the interests of the care workforce, and that are based on a realistic evaluation of important factors such as the role of older people in providing unpaid care? A focus on policy ideas includes a focus on policy debate, which often means once again arguing against facile generational arguments. Constantly trying to quash zombie ideas is frustrating work, but it is not clear why stopping will help. Ceasing to try to argue with zombie ideas merely sets them up to become the conventional wisdom.

One point to underline in thinking about the policies is that lifecourse analysis is often taken to mean a focus on the young: a point of view that can be caricatured as the idea that the optimal return on investment in a person is a few months before birth, with declining returns every day afterwards. Life-course approaches mean what the term says: approaches over the life-course, which can and should include effective assistance and interventions at all ages. Life ends only at death, and so should life-course interventions.

A second step is coalitional politics. What are some organized groups with an interest in positive-sum approaches to health policy, including policies relevant to ageing? It includes groups with a commitment, based on a formulated understanding of their interests, to a sustainable approach to ageing and social care. Organized groups can do two things that disorganized voters, focused on other issues, cannot: formulate and debate complex policy options, and identify longer-term sustainability threats and possibilities.

A number of these organized groups stand out from our analysis. One is providers of health care and social care, whose interests in being financed to make any adaptations can lead to an interest in a quality and well structured system. Another is the formal caring workforce, typically organized, if organized at all, by public sector unions. They likewise have an incentive to promote a fiscally sustainable, high quality model of care, and to undercut insider/outsider divides that unions in other sectors can often promote. The formal caring workforce, like 
the informal caring workforce, is predominantly female, and women are at the centre of any likely sustainable policy solution. Women's movements can opt for many different definitions of the problems that women face, and their internal politics are complex and filled with their own representational inequalities. That makes their decisions particularly interesting, and shows the importance of highlighting the gender dimensions of this issue, on the level of individuals as well as society. Such an understanding has changed politics to a surprising degree, for example in Japan (Schoppa, 2010). Policymakers themselves can be important members of coalitions; health ministry officials, for example, will often have awareness of good and plausible policy options and skills at promoting them in coalition. Finally, organizations representing the elderly, especially the better established, have an interest in solutions that reflect the unselfishness of many elderly voters (who can care about their society and children as much as anybody) and in policy solutions that will be fiscally and politically sustainable over time.

This is a message of optimism. Instead of deterministic theories that read inexorable conflict and policy change from demographics, we have a world of complex coalitions and debates about policy ideas and agendas. The supply of ideas can be shaped by small numbers of people with policy skills, and the development of coalitions is flexible and can always offer new opportunities and ideas. Policy ideas that move towards positive-sum relations between people and groups and away from simple constraint and comparison can be developed. Instead of trying to infer inevitable policy from demographic patterns, we can embrace the complexity of politics and the possibilities that it brings. Instead of assuming, or creating, a zero-sum struggle between the generations, we can get positive-sum life-course policies. Instead of a world of winners and losers, we can make win-win policies. But we need to get the politics right. 